\title{
AÇÃO AFIRMATIVA E O COMBATE AO RACISMO INSTITUCIONAL NO BRASIL
}

\author{
VALTER ROBERTO SILVÉRIO \\ Professor Adjunto do Departamento de Ciências Sociais da Universidade Federal \\ de São Carlos \\ silverio@power.ufscar.br
}

\begin{abstract}
RESUMO
O artigo analisa o debate sobre ação afirmativa no Brasil à luz da bibliografia sobre racismo e sobre os fundamentos jurídicos da igualdade de oportunidades. A partir desta perspectiva, polemiza com as visões que criticam a implementação de políticas compensatórias, reunindo evidências sobre a participação do Estado na legitimação da discriminação racial no país. Ta/ envo/vimento é explorado na instituição escolar, examinando-se as conseqüências do preconceito sobre a identidade e a auto-estima das crianças e jovens negros.

RACISMO-DISCRIMINAÇÃORACIAL - IGUALDADEDEOPORTUNIDADES-POLITICA SOCAL-EDUCAÇÃO
\end{abstract}

\section{ABSTRACT}

AFFIRMATINEACTIONAND THEFIGHTAGAINSTINSTITUTIONAL RACISMINBRAZIL. This article analyzes the debate on affirmative action in Brazil in the light of the bibliography about racism and the legal basis for equal opportunities. From this perspective, it challenges the critical visions to the implementation of reparatory policies, gathering evidence on the state's participation in the legitimation of racial discrimination in the country. Such involvement is explored in the school institution context, examining the consequences of prejudice on the identity and selfesteem of black children and youth.

RACISM-RACIAL DISCRIMINATION - EQUAL OPPORTUNITIES - SOCIAL POLICIESEDUCATION

Este trabalho teve como colaboradoras: Andrea Barreto Rodrigues, Tatiane Cosentino Rodrigues, Vanessa Mantovani Bedani, alunas do $4^{\circ}$ ano de pedagogia, e Ana Elisa De Carli, aluna do $4^{\circ}$ ano de ciências sociais da UFSCar. 
O recente debate sobre cotas no Brasil, no meu entender equivocado, tem permitido trazer para a superfície da discussão sociopolítica do país os problemas dos grupos historicamente discriminados. O equívoco consiste em enfatizar a modalidade mais polêmica das políticas de ação afirmativa. Tais políticas têm servido, em vários países, para minimizar os pesados custos sociais para populações que foram colonizadas, externa e internamente, em países hoje considerados multirraciais e ou multiétnicos, que procuram pautar-se pela construção e aprofundamento dos ideais democráticos.

Em linhas gerais debater em torno da aceitação ou não-aceitação das cotas, além de empobrecer a discussão de conteúdo, significa perder a oportunidade de levantar e tentar responder à seguinte questão: Como podemos incluir minorias historicamente discriminadas, uma vez que as políticas universalistas não têm tido o sucesso almejado, e, ao mesmo tempo, debater em que bases é possível rever aspectos fundamentais do pacto social?

Nas páginas seguintes tento responder a esta questão discutindo, não de forma exaustiva, alguns aspectos que considero fundamentais no debate sobre as políticas públicas de ação afirmativa. Um primeiro aspecto importante é com relação ao princípio de igualdade', como aquele que tem servido de base a todas as sociedades democráticas ou em vias de democratização, mas que na atualidade tem-se colocado mais como obstáculo às mudanças do que operado no sentido de propiciar tratamento diferenciado a quem a sociedade tem tratado desigualmente. Um segundo aspecto presente no debate contemporâneo, com profundas implicações para as políticas públicas de ação afirmativa, é a discussão sobre o estatuto da raça como uma categoria válida para a explicação e compreensão das desigualda-

I A crença de que as sociedades deveriam aspirar a tratar seus membros de maneira mais igualitária, no sentido tanto formal quanto material, ocupa uma posição central no pensamento desenvolvido no século $X X$. Nos séculos XVIII e XIX o ideal manifestou-se na exigência de direitos iguais diante da lei e direitos iguais de participação política. No século $X X$ esses tipos de igualdade já eram dados como certos (na teoria, ainda que nem sempre na prática) em todas as sociedades avançadas, e a atenção concentrou-se numa nova exigência: a igualdade social. Por igualdade social entende-se a idéia de que as pessoas devem ser tratadas como iguais em todas as esferas institucionais que afetam suas oportunidades de vida: na educação, no trabalho, nas oportunidades de consumo, no acesso aos serviços sociais, nas relações domésticas e assim por diante. Mas, que significa ser tratado com igualdade? Falando de maneira ampla, houve duas respostas a essa pergunta altamente controvertida, que podemos rotular, respectivamente, de igualdade de oportunidades e igualdade de resultados (Outhwaite, Bottomore, 1996, p.372-373). 
des sociais. Finalmente, a discussão em torno das políticas de ação afirmativa como uma via alternativa de resolução dos conflitos resultantes das desigualdades raciais e de gênero tem implicado uma profunda revisão dos pressupostos do liberalismo ou, mais precisamente, dos limites e possibilidades daqueles pressupostos para a solução de problemas contemporâneos.

Em interessante artigo intitulado "O princípio da igualdade e a escola", Comparato (1998), para tecer considerações sobre tal princípio, parte da distinção entre diferenças sociais e desigualdades sociais. Assim, as diferenças sociais têm uma base natural ou são produto de uma construção cultural. No primeiro caso, um exemplo comum é a diferença entre os sexos. No segundo caso, a diferença funda-se num complexo agregado de costumes, mentalidades etc., que confere uma mesma visão de mundo e ou uma mesma tradição tribal ou grupal, possibilitando distinção em relação aos demais. Aqui estamos falando da identidade como atribuída e ou construída.

Seguindo em sua argumentação, o autor afirma que as desigualdades sociais, de maneira distinta das diferenças sociais, têm por base um juízo de superioridade e inferioridade entre grupos, camadas ou classes sociais. Assim, o problema pode ser esboçado da seguinte forma: desde o surgimento do liberalismo existe uma tendência, ou ao menos uma preocupação de eliminar, paulatinamente, as desigualdades sociais. A questão é como fazer a distinção entre aquilo que é o reconhecimento de uma diferença natural ou cultural e, portanto, preservar essa diferença e, por outro lado, eliminar as desigualdades sociais (Comparato, 1998, p.47-48).

Após afirmar que a desigualdade social é marca registrada da sociedade brasileira, desde os seus primórdios, e associá-la à nossa origem ibérica², autor identifica dois focos principais de geração de desigualdades sociais no Brasil. O primeiro, que considera o mais importante, é a desigualdade entre ricos e pobres. $\bigcirc$ segun-

2 Para Comparato, a persistência das profundas desigualdades sociais, entre os brasileiros, estaria associada ao desenvolvimento e reprodução de um caldo de cultura peculiar aos povos ibéricos, denominado por ele de individualismo anárquico. A característica principal desse individualismo anárquico seria um culto à pessoa em detrimento do grupo ou conjunto, impedindo formas de coesão social e de apreciação coletiva, em especial, de leis e normas jurídicas que pudessem orientar o conjunto da sociedade. "No fundo de cada brasileiro, de cada ibérico, se quiserem - isso herdamos dos nossos colonizadores -, existe esta convicção, de que nós somos "um", indiscutivelmente um diferente dos demais, e que, portanto, não pode ser comparado e, se não pode ser comparado, não há como pensar em igualar" (Comparato, 1998, p.49). 
do, que afirma ser também forte mas de menor importância quando comparado ao primeiro, é a desigualdade entre brancos e negros (Comparato, 1998, p.54).

A desigualdade entre ricos e pobres seria a principal fonte de preconceitos e atritos e o grande fator de atraso da sociedade brasileira. E é inconsciente. A desigualdade entre brancos e negros, decorrente da escravidão ${ }^{3}$, seria a principal fonte de geração e manutenção de hierarquias sociais vinculadas ao pertencimento racial. Em síntese, a junção entre o desprezo pelo trabalho físico, posse de empregados e o preconceito contra pobre contrastaria com o prestígio intelectual embutido em nossa "doutorice". Negando-se a ficar no plano do diagnóstico, Comparato parte para o remédio prioritário para reverter o quadro de desigualdade social no Brasil: a educação.

Uma discordância em relação ao diagnóstico acima é possível. É, precisamente, o fato de atribuir-se à desigualdade entre ricos e pobres a proeminência da explicação sobre os profundos problemas sociais do país. Creio que as desigualdades são um produto de uma trama complexa entre o plano econômico, político e cultural. Além disso, a multiplicidade de fatores na explicação das desigualdades tem a vantagem de mostrar tanto a multicausalidade dos elementos explicativos da vida social quanto o aspecto dinâmico e relacional das relações sociais.

Mesmo se se considerar a proeminência da desigualdade entre ricos e pobres na explicação dos fenômenos sociais, o modo como ela se expressa na contemporaneidade brasileira é problemático, uma vez que os indicadores sociais mostram uma confluência entre desigualdade econômica e desigualdade racial ${ }^{4}$. Estes estudos demonstram que a dimensão econômica explica apenas parte das desigualdades entre negros e brancos, a outra parte é explicada pelo racismo, e a discriminação racial teve uma configuração institucional, tendo o Estado legitimado historicamente o racismo institucional.

Uma outra ordem de problemas que aparece no texto de Comparato é a visão de um individualismo não anárquico, característico do verdadeiro liberalismo, versus um individualismo anárquico, que seria a origem de todas as nossas mazelas.

3 Dentre as múltiplas conseqüências da escravidão para a sociedade brasileira, Comparato assinala a universalidade, isto é, o fato de o escravo ser trabalhador e o "companheiro" de casa e, como decorrência, a idéia de que nos afirmamos socialmente pelo fato de possuirmos empregados (Comparato, 1998, p.55).

4 Ver, a este respeito, os trabalhos do Instituto de Pesquisa Econômica Aplicada - IPEA - , em especial o estudo de Ricardo Henriques (200I). 
De certa forma, o modo como Comparato coloca o problema já contém uma resposta que se estrutura baseada em nossa origem ibérica e pelo nosso "liberalismo" deformado. Assim, minha proposta é recolocar o problema da desigualdade social entre brancos e negros como uma dimensão fundamental da explicação da desigualdade entre ricos e pobres. Acredito que as discriminações e os racismos são componentes essenciais na conformação da sociedade brasileira e operam menos no plano individual e mais no plano institucional e estrutural.

Retomando o pressuposto que toda desigualdade se estrutura a partir de um juízo de superioridade, aparentemente os negros, desde que foram trazidos para as terras brasileiras, estiveram submetidos a todo tipo de juízos, normalmente negativos e pejorativos, sobre sua condição de diferente no plano sociocultural. Assim, o modo como as diferenças naturais e culturais são construídas socialmente, na forma de desigualdades sociais, torna-se um problema científico e político nas sociedades contemporâneas multirraciais.

\section{RAÇA E DESIGUALDADE SOCIAL}

Concordo com Omi e Winant ( 1994$)$ que raça não é apenas algo a mais, isto é, algo que é adicionado, mas é, sim, parte integrante e constitutiva de nossas experiências cotidianas mais comuns. No Brasil, no entanto, existiu e existe uma tentativa de negar a importância da raça como fator gerador de desigualdades sociais por uma parcela significativa dos setores dominantes. Só muito recentemente vozes dissonantes têm chamado a atenção sobre a singularidade de nossas relações raciais.

Andrews, por exemplo, tenta mostrar como o sistema de categorização racial brasileiro tem sido dinâmico no tratamento da mistura de raças. $\bigcirc$ centro do debate tornou-se a existência de uma categoria racial intermediária, que aparece normalmente nomeada como mulato, pardo e ou moreno, que seria o fator de distinção do sistema classificatório brasileiro.

"Ao contrário do 'pardo' ou do 'preto', o 'moreno' não indica automaticamente ancestralidade africana" (Andrews, 1998, p.385). As discordâncias sobre o modo de categorizar os morenos no sistema brasileiro podem desvendar a dimensão política da nossa classificação racial. No fundamental, o moreno seria uma categoria dissolvente da polaridade negro e branco, isto é, nele estaria contida a síntese brasileira. O próprio Andrews vai mostrar, por meio de suas pesquisas empíricas, que tal suposição ou imposição não se sustenta. 
A característica básica do modelo brasileiro de classificação racial, quando contrastado com o modelo norte-americano, por exemplo, é a multipolaridade. De acordo com Fry, "o modo múltiplo permite que os indivíduos possam ser classificados de distintas maneiras. [...]. Permite o que podemos chamar de 'desracialização' da identidade individual" (Fry, I995/I996, p. I32-133). Para este autor, um indicador da desracialização estaria na possibilidade de aplicação do termo "moreno" e "moreninho" à uma grande gama de "aparências" que podem incluir descendentes de europeus e descendentes de africanos, entre outros.

A característica básica do modelo americano, de acordo com os antropólogos, é a bipolaridade com base na hipodescendência, conhecida na cultura popular dos EUA como a "regra de uma gota só" (one drop rule). De acordo com Gilliam, a hipodescendência implica uma situação na qual a pessoa herdaria ad infinitum a identidade social do progenitor menos prestigiado geração após geração. A autora chama a atenção para o fato de que a hipodescendência só se refere a pessoas de descendência africana; nenhum outro grupo teve que se debater com este modelo de identidade social (Gilliam, 2000, p.94).

Fry reconhece que ambos os modos de classificação são baseados em noções neolamarckianas de descendência, portanto, são racistas. Mas, de acordo com o autor, o modo bipolar produziria um mundo de raças essencializadas (apud Gilliam, 2000, p.93). Para o autor, "o movimento negro quis romper com o modo múltiplo de classificação, mudando as regras do jogo. E o fez com tanta energia que começou a negar qualquer especificidade brasileira, descrevendo o país como "pior que o apartheid, por exemplo" (Fry, 1995/1996, p. 132-133).

Segundo Gilliam, Fry "está correto ao associar a crítica ao modelo bipolar dos Estados Unidos com a intenção original de proteger os brancos contra a poluição biológica" (2000, p.94). Mas, o apelo para que os brasileiros se orientem pela expressão multipolar resulta em não admitir a existência da expressão bipolar à brasileira para um amplo setor da população afrodescendente, que não tem conseguido desracializar sua identidade individual, mesmo quando quer. Isso se deve às marcas corpóreas e aos permanentes atributos "carinhosos" do cotidiano popular brasileiro, que nem sempre estão presentes nas universidades e centros de pesquisa, tais como "aquele negão", "aquela neguinha assanhada" ou o famoso "só podia ser preto". Assim, se a ambigüidade tem sido um traço característico de nossa classificação racial, ela não tem impedido que uma parcela significativa da população negra seja permanentemente racializada no cotidiano e que, por isso mesmo, tenha assumido sua identidade negra de forma não ambígua e contrastante em relação ao seu outro, o branco. Essa assunção não ambígua, aparentemente, 
desvenda a intrincada trama do nosso universo de classificações que tem permitido, por meio do uso e abuso da multipolaridade, a subordinação funcional dos não-brancos.

Dentre várias evidências citadas por Andrews em relação ao peso relativo da "morenidade", para plasmar a identidade sociorracial vale relembrar a referência aos arquivos do jornal O Estado de S. Paulo, um dos principais do país.

O Estado mantém arquivos classificados por tópicos sobre uma variedade de temas, incluindo "Negros no Brasil". O arquivo sobre os negros, que remonta à década de 1880, contém três grossas pastas e centenas de artigos. Para meados de 1988, o arquivo sobre mulatos continha oito artigos. Isto reflete dois fatos: que os jornalistas de São Paulo que escreveram sobre os afro-brasileiros durante o último século tenderam a agrupá-los sob o título de negros; e mesmo quando esses jornalistas distinguiram entre pretos e pardos, os arquivistas de O Estado continuaram a agrupálos em uma única categoria de "negros". A categoria racial do mulato, supostamente tão importante no Brasil, mal parece ter surgido na consciência destas pessoas. (Andrews, 1998, p.384)

Outro aspecto fundamental observado por Andrews é o vínculo entre o racismo institucional e a política estatal. $\bigcirc$ autor encontra evidências da relação entre o governo estadual (em São Paulo) e os proprietários rurais de terras para fomentar o desenvolvimento econômico, subsidiar a imigração européia e impedir a diversificação profissional entre os afro-brasileiros recém libertos (Andrews, 1998, p.50).

Para Andrews e Hanchard, a escravidão é somente uma das diversas variáveis explicativas a serem consideradas para determinar por que, em I889, ou seja, apenas um ano depois da Abolição - os trabalhadores afro-brasileiros foram afastados da competição "objetiva" de mercado em São Paulo. Na avaliação desses autores, na imigração de europeus meridionais e no tratamento diferencial concedido aos novos imigrantes, em detrimento dos afro-brasileiros, encontram-se um grau de dirigismo e intervenção estatal incomuns (Andrews, 1998, p.93- 147; Hanchard, 200 I, p.29-59).

Assim, as classificações, embora importantes, não dão conta dessa dimensão objetiva que representou a presença do Estado na configuração sociorracial da força de trabalho no momento da transição do trabalho escravo para o trabalho livre, nem da ausência de qualquer política pública voltada à população ex-escrava para integrá-la ao novo sistema produtivo. Daí poder afirmar que a presença do Estado foi decisiva na configuração de uma sociedade livre que se funda com profunda exclusão de alguns de seus segmentos, em especial da população negra. 
Concordo com Emília Viotti da Costa que "para explicar as percepções que as pessoas têm dos padrões raciais, seria preciso investigar fora do âmbito estreito das relações raciais" (1985, p.238). Somente dessa maneira é que poderíamos, no caso brasileiro e latino-americano, incorporar os avanços recentes na conceituação da política racial e étnica.

Ao contrário de uma geração de estudiosos, que tentou fundir raça com etnia, a compreensão teórica mais recente da formação das identidades raciais estabelece uma distinção entre as duas, nos contextos em que o fenótipo (aquilo que definimos como raça) torna-se uma questão de maior destaque do que a língua, a cultura ou a religião. (Hanchard, 200 I, p.29)

Entre outras implicações dessa nova forma de compreensão vale destacar duas: a primeira tem relação com o modo pelo qual os estudiosos vêem a raça e a etnia; a segunda vincula-se à "transnacionalização" dos movimentos sociais latinoamericanos. No primeiro caso, os estudos destacam que alguns grupos "étnicos" são assimilados, independentemente do momento histórico, por sua adequação "racial" ao grupo dominante, enquanto para outros grupos "étnicos" a diferença fenotípica transforma-se em uma marca. No segundo caso, especialmente, entre os "índios" e os "negros"

...fatores externos e internos levaram a uma crescente identificação racial com outros grupos fenotipicamente semelhantes, que passaram pela escravidão racial e por outras formas de opressão nas relações com as elites criollas, descendentes de europeus. Essa identificação de uma comunidade fora das fronteiras dos Estados nacionais enfatiza os entrelaçamentos da identidade racial, nacional e cultural. (Hanchard, 2001, p.30)

Em linhas gerais, o que o autor quer destacar é que o termo raça, contemporaneamente,

...refere-se ao emprego das diferenças fenotípicas como símbolos de distinções sociais. Os significados e as categorias raciais são construídos em termos sociais, e não biológicos. Esses símbolos, significados e práticas materiais distinguem sujeitos dominantes e subordinados, de acordo com suas categorizações raciais. (Hanchard, 200 I, p.30)

Assim, a raça, para além de um marcador da diferença fenotípica, tem sido utilizada como status de classe (ou grupo) e de poder político (Gilroy, 1987; Hall, 1986, 1992). 
Nesse caso, do meu ponto de vista, reside o divisor de águas entre novas e velhas abordagens sobre a raça e, obviamente, a possibilidade de uma compreensão contemporânea da potencialidade que as políticas públicas compensatórias tem de solucionar, mesmo que de modo parcial e temporário, os problemas gerados pelas desigualdades sociais com base no pertencimento a um grupo racial.

Gilroy, por exemplo:

...sugere que raça funciona como um conduto entre a cultura e a estrutura social, entre os sentidos e valores que os grupos atribuem às diferenças raciais e a escolha, a imposição e o reforço desses sentidos e valores nos mercados de trabalho, no aparelho de Estado e nas instituiç̧ões políticas, sociais e culturais. (apud Hanchard, 2001, p.31)

Essa sugestão de Gilroy faz relembrar a existência, até muito recentemente, de inúmeros anúncios em "cadernos de empregos", dos principais jornais brasileiros, que exigiam boa aparência, o que, aparentemente, excluía os negros e "morenos" de várias possibilidades de emprego, independentemente do grau de escolarização e da competência profissional. No aparelho de Estado, a meu ver, a ausência de políticas públicas substantivas em relação à habitação popular de qualidade, ao atendimento à saúde e à educação, reflete o descaso para com aqueles milhões de brasileiros que são considerados inferiores, segundo o juízo de superioridade das elites e dos setores intermediários, os quais supostamente tiveram mobilidade por mérito técnico e profissional.

\section{OS ANOS DE 1990}

Resultado de uma árdua luta realizada pelos movimentos negros nas duas décadas anteriores, nos anos 90 do século $X X$ presenciamos uma mudança de postura significativa, em todos os segmentos da sociedade brasileira, em relação ao tratamento das questões da população negra no país. Dentre os fatores que mais contribuíram para a maior visibilidade das desigualdades sociais entre negros e brancos podem-se destacar o aumento e a divulgação de pesquisas empíricas; o surgimento de vários conselhos de desenvolvimento e participação da comunidade negra, no plano estadual e municipal; e o reconhecimento oficial, em 20/I I/I995, no plano federal, da existência da discriminação racial e do racismo, com a implantação por meio de decreto do Grupo de Trabalho Interministerial - GTI -, com a função de estimular e formular políticas de valorização da população negra. 
É, portanto, sintomático que, na década de 90 do século $X X$, alguns intelectuais tenham observado a necessidade de ampliar os estudos pós-abolição, tentando mensurar de modo mais sistemático e preciso as desigualdades a que os negros estavam submetidos em nosso país, e também passado a assumir uma posição, sugerindo medidas necessárias para diminuir as distâncias sociais entre negros e brancos.

Hasenbalg, por exemplo, observava, em 1992, que com os estudos existentes sobre as desigualdades raciais já seria possível intervir de três maneiras na correção de distorções. Em primeiro lugar, por meio do caminho jurídico utilizando a legislação que pune o racismo como crime. Em segundo lugar, pela aplicação de ações afirmativas que, de acordo com o autor, visariam à igualdade entre grupos no plano dos direitos e consistiriam no tratamento preferencial baseado no pertencimento a grupos (de raça ou gênero) para compensar a discriminação no passado. Para Hasenbalg, dois obstáculos interpor-se-iam para tal implantação: a ausência de apoio político e o sistema de classificação racial brasileiro (dificuldade de identificar quem é não branco). Finalmente, as políticas não racialmente específicas que, segundo o autor, possuem caráter redistributivo e se constituem em programas variados para combater a pobreza nas suas raízes. Estas últimas irão sempre depender, em grande medida, "do tipo de governo eleito, da correlação de forças políticas e da obtenção de um padrão de desenvolvimento sustentado que facilite a redistribuição" (Hasenbalg, Silva, 1992, p. I5).

Apesar dos obstáculos apontados por Hasenbalg, no Brasil, a segunda metade dos anos de 1990 é marcada, dentre outros temas, pela introdução do debate sobre a ação afirmativa. $\bigcirc$ debate gira, aparentemente, em torno das mudanças ocorridas no pensamento social a partir do final da Segunda Grande Guerra e suas implicações para a ação coletiva e para a ação estatal nos Estados Unidos. Desse modo podemos aprender com a discussão sobre a ação afirmativa (affirmative action) e a identificação de distorções sociais, ao considerar o credo americano e a realidade sobre a qual foram e são aplicadas aquelas políticas públicas e, também, suas repercussões no contexto brasileiro.

\section{AÇÃO AFIRMATIVA E ESTRUTURA SOCIAL}

Uma das polêmicas centrais no debate sobre ação afirmativa na dimensão normativa trata da complexidade e da variabilidade do princípio da igualdade jurídica, ou seja, a 
...dificuldade de alcançar uma formulação precisa e, especialmente, o incessante esforço na tentativa de assegurar a sua aplicação - o que repercute na busca pela própria justiça - confundem-se, sob um determinado prisma com a evolução do direito constitucional moderno. (Menezes, 200 I, p. I5)

Existe um certo consenso entre os estudiosos da área do direito de que, a partir do advento da Declaração de Direitos da Virgínia (em I2/06/l776), reconhecido como o documento precursor das modernas declarações de direitos fundamentais, o tema da igualdade passa a ter um grande desenvolvimento no plano jurídico. As mudanças estimuladas pelo desenvolvimento do capitalismo no mercado teriam provocado a transição do princípio jurídico da igualdade de todos perante a lei, isto é, de um princípio isonômico ou formal - que, aparentemente, permitiria um mesmo tratamento normativo para todos os indivíduos - para um princípio de igualdade material ou substantiva. Assim, o princípio jurídico da igualdade teria deixado de ser apenas um sustentáculo do Estado de direito para ser um dos pilares do Estado social (Menezes, 200 I, p.20-26).

Essa mudança sintetizava o avanço das reivindicações dos movimentos operários do século XIX, que lutavam incessantemente pela melhoria das condições de vida e trabalho. Essas lutas originaram tanto as propostas socialistas quanto o Welfare State.

No plano político o princípio da igualdade significou o voto eqüivalente entre todos os homens, isto é, um homem, um voto. As dificuldades de aplicação do princípio de igualdade residiram e residem na dimensão socioeconômica ou, mais precisamente, na sua implementação no âmbito do mercado em geral e, em especial, no mercado de trabalho. $O$ fato é que durante todo o século $X X$ os exescravos, ex-colonos e as mulheres em vários países ocidentais travaram e continuam travando verdadeiras batalhas pela inclusão e pelo tratamento igualitário em todas as esferas da vida social, ao mesmo tempo em que repudiaram e repudiam todas as formas de discriminação com base nas diferenças naturais e exigem o reconhecimento de suas particularidades, uma vez que estas foram e são construídas socialmente como desigualdades. Após a Segunda Grande Guerra Mundial, às lutas dos trabalhadores por melhores salários e condições de vida somaram-se as lutas das mulheres, dos negros, de grupos étnicos, que passaram a exigir uma ação do Estado para assegurar a igualdade de oportunidades no mercado de trabaIho e na educação.

Vários autores registram que a década de 1960 pode ser considerada aquela na qual se originaram movimentos sociais que estimularam mudanças sociais pro- 
fundas na dinâmica das sociedades ocidentais. Tais mudanças repercutiram sobremaneira nos esquemas interpretativos das ciências sociais. $\bigcirc$ dicionário do pensamento social do século $X X$, por exemplo, registra as características que se seguem estudadas pelos teóricos em relação aos novos movimentos sociais. A maioria dos autores concebe as ações em termos de comportamento coletivo conflitante que abre espaços sociais e culturais; tais movimentos são encarados como instituições politizantes da sociedade civil, redefinindo, dessa forma, as fronteiras da política institucional; oferecem, mediante sua própria existência, um modo diferente de designar o mundo e desafiar os códigos culturais predominantes sobre bases simbólicas; criam novas identidades que compreendem exigências inegociáveis; expressam processos de aprendizado coletivo evolutivo; constituem novas articulações sociais que cristalizam novas experiências e problemas em comum, na esteira de uma desintegração geral da experiência baseada na classe econômica. $\bigcirc$ significado geral que essas formulações conferem aos novos movimentos sociais é que eles ganham maior consciência de sua capacidade de produzir novos significados e novas formas de vida e ação social (Outhwaite, Bottomore, 1996, p.502).

No que diz respeito às relações raciais, Guimarães, por exemplo, observa que, por volta dos anos de 1960,

... a ciência social começa a abandonar os esquemas interpretativos que tomam as desigualdades raciais como produtos de ações (discriminações) inspiradas por atitudes (preconceitos) individuais, para fixar-se no esquema interpretativo que ficou conhecido como racismo institucional, ou seja, na proposição de que há mecanismos de discriminação inscritos na operação do sistema social e que funcionam, até certo ponto, à revelia dos indivíduos. (1999, p. 156)

Este mesmo autor observa, também, que na ciência política foi a época em que as análises clássicas de poder e dominação de Dahl e Lipset cederam lugar a análises sobre o "poder sistêmico", feitas por estudiosos como Barach e Baratz, Steven Lukes e outros (Guimarães, 1999, p. I56).

Essa mudança pode ser considerada uma evolução ou, no mínimo, um deslocamento profundo do pensamento social. As características principais desse processo foram a "descoberta" e a teorização de fenômenos sociais irredutíveis ao indivíduo que conduziram a teoria do direito, e o próprio pensamento liberal, à busca de novas formas de compatibilização entre direitos individuais e restrições à ação individual (Guimarães, 1999, p. I56).

Por meio desse debate, que ganha ampla visibilidade nos anos 70/80, é possível observar tanto as atualizações quanto as resistências à incorporação de 
novos esquemas interpretativos pela ciência social e pela ciência política. Uma análise sucinta das políticas públicas de ação afırmativa implementadas a partir da década de 60 na sociedade norte-americana permite, de modo inicial, observar a extensão das mudanças em curso tanto na teoria quanto nas práticas sociais.

\section{A JURISPRUDÊNCIA AMERICANA E AS AÇÕES AFIRMATIVAS}

A expressão ação afirmativa, segundo Jones ( 1993, p.345), refere-se a "ações públicas ou privadas, ou programas que provêem ou buscam prover oportunidades ou outros benefícios para pessoas, com base, entre outras coisas, em sua pertença a um ou mais grupos específicos".

A primeira referência à "ação afirmativa" aparece, com esse sentido, na legislação trabalhista de 1935 (The 1935 National Labor Relations Act), prevendo que

...um empregador que fosse encontrado discriminando contra sindicalistas ou operários sindicalizados teria que parar de discriminar e, ao mesmo tempo, tomar ações afirmativas para colocar as vítimas nas posições onde elas estariam se não tivessem sido discriminadas. (Guimarães, 1999, p. 154)

A idéia básica vem do centenário conceito inglês de eqüidade (equity), ou de administração da justiça de acordo com o que era justo numa situação particular, por oposição à aplicação estrita de normas legais, o que pode ter conseqüências cruéis.

A antiga noção de ação afirmativa tem, até os dias de hoje, inspirado decisões de cortes americanas, conservando o sentido de reparação por uma injustiça passada. A noção moderna se refere a um programa de políticas públicas ordenado pelo executivo ou pelo legislativo, ou implementado por empresas privadas, para garantir a ascensão de minorias étnicas, raciais e sexuais. (Guimarães, 1999, p. 154 )

Uma das questões centrais no debate sobre as políticas públicas de discriminação positiva é, precisamente, sob quais princípios de direito baseiam-se as leis e os programas referidos como ações afırmativas?

As desigualdades sociais combatidas pela ação afirmativa originam-se, normalmente, de práticas sistemáticas de algum tipo de discriminação negativa. Essa foi a primeira justificativa que possibilitou tratar diferenciadamente um grupo social. $\mathrm{Na}$ atualidade, entretanto, o alcance de tais ações ampliou-se e alguns juristas e estudiosos do tema sustentam que elas podem e devem ser empregadas para a promoção de maior diversidade social, uma vez que essas políticas podem propiciar a ascensão e 
o fortalecimento de grupos sub-representados nas principais posições da sociedade. De modo geral, as discussões giram em torno de três perspectivas, em que duas correspondem a uma forma de justiça reparatória (compensatória) ou distributiva e uma terceira, de caráter preventivo, que teria a intenção de coibir que grupos com grande probabilidade de serem discriminados sofram tal processo.

Gomes, por exemplo, classifica as políticas governamentais norte-americanas de combate à discriminação como "neutras", isto é, constituídas pelas normas meramente proibitivas de conteúdo inibitório ${ }^{5}$, e como ações afirmativas, decorrentes de políticas públicas concebidas pelo poder executivo com o apoio dos poderes legislativo e judiciário. De acordo com esse autor, o Estado norte-americano atua, nas ações afirmativas, com base na chamada Spending Clause da constituição, que pressupõe o dispêndio de recursos públicos para causas de interesse coletivo. No interior das políticas afirmativas, o autor identifica dois tipos: as ações reparadoras ou restauradoras e as ações redistributivas (Gomes, 200 I , p.53).

Na primeira perspectiva, a ação afirmativa reparatória (compensatória) teria a função de ressarcir os danos causados, tanto pelo poder público quanto por pessoas físicas ou jurídicas, a grupos sociais identificados ou identificáveis.

Nessa forma de ação é fundamental que somente os responsáveis sejam penalizados e que as vítimas reais, reconhecidas individualmente, sejam total ou parcialmente ressarcidas. Dessa forma, evita-se a chamada discriminação reversa ${ }^{6}$, isto é, o favorecimento daqueles que não foram vítimas de discriminação.

Na perspectiva distributivista, a ação afirmativa estaria relacionada a uma igualdade proporcional, exigida pelo bem comum, na distribuição de direitos, privilégios e ônus entre membros da sociedade, que pode ser implementada por meio de vários artifícios com o objetivo de diminuir ou eliminar as iniqüidades decorrentes da discriminação (Menezes, 200 I , p.38; Gomes, 200 I , p.66).

Duas vertentes principais podem ser observadas no interior da perspectiva distributivista.

5 O Estatuto dos Direitos Civis de 1964 divide-se em inúmeros capítulos, cada um deles dedicado a uma forma específica de discriminação, entre outras discriminação no emprego, no acesso à educação, quanto à residência, religiosa, em razão de deficiência física. $\bigcirc$ traço característico dessa modalidade de combate à discriminação é tratar-se de normas meramente dissuasórias e proibitivas das práticas discriminatórias, aparentemente, com pouca eficiência prática (Gomes, 200 I , p. 52).

6 Otermo reverse discrimination (discriminação reversa) é amplamente utilizado pelos opositores das políticas de ação afırmativa. 
A primeira baseia-se na idéia da igualdade ao nascer (equality at birth). $\bigcirc$ argumento central é que no momento do nascimento inexistem fatores de distinção relevantes entre as pessoas, a não ser aqueles de ordem natural, tais como raça e sexo, os quais, por sua própria natureza, não se revestem de maior importância para efeito de aferição de futura inteligência ou capacitação (Gomes, 200 I, p.67). Assim, as diferenças são produto da vida em sociedade, que têm como principal matéria-prima os valores.

A segunda vertente ancora-se em argumentos utilitaristas, ao sustentar que não obstante o objetivo da ação afirmativa ser o de favorecer a maior participação de determinados grupos (negros e mulheres, por exemplo) em certas posições e profissões no mercado de trabalho, portanto, na sociedade, a sua finalidade última é a redução substantiva ou eliminação das desigualdades sociais relacionadas com a divisão do poder e da riqueza (Gomes, 200 I , p.69; Menezes, 200 I , p. 38).

Dworkin, um dos expoentes dessa vertente, afirma, com base em sua leitura da Constituição federal norte-americana, que esta, por meio do princípio de igualdade, impede não apenas a chamada discriminação subjetiva, mas também a discriminação estrutural. Como discriminação estrutural entendam-se padrões socioeconômicos díspares entre as pessoas, em decorrência de injustiças sociais de toda ordem, educação deficiente e insuficiente, preconceitos que interferem e influenciam as perspectivas de vida das pessoas. Para o autor, a erradicação dessas formas de discriminação seria moralmente legítima e juridicamente uma meta pública racional e necessária (Dworkin, 1978, 1985, 1996). A ação afirmativa, nesta perspectiva, seria uma mecanismo fundamental de combate à discriminação e ao racismo estrutural.

Assim, a aplicação dos princípios da justiça distributiva, em sua versão discutida por John Rawls, possibilitaria tanto a igualdade de oportunidades como o combate a desigualdades não justificáveis socialmente. Na prática, estas políticas reconhecem oficialmente, por um lado, a persistência da perenidade das discriminações e do racismo e, por outro lado, têm como meta a implantação de políticas públicas voltadas à ampliação da diversidade e do pluralismo em todas as dimensões da vida social (Gomes, 200 I, p.44-45).

Dito de outro modo, para além do ideal de concretização da igualdade de oportunidades, figuraria, entre os objetivos almejados com as políticas afirmativas, o de induzir transformações de ordem cultural, pedagógica e psicológica, aptas a subtrair do imaginário coletivo a idéia de supremacia e de subordinação de uma raça em relação a outra, do homem em relação à mulher etc. (Gomes, 200 I, p.44). 
Aqui reside, aparentemente, um aspecto distintivo entre as perspectivas jurídica e política em relação à ação afirmativa. A distinção está na análise segundo a qual, não obstante o papel desempenhado pelos tribunais americanos na implementação dos programas de ação afirmativa, estes atuaram de modo corretivo e não propositivo.

Em outra linha de argumentação, Guimarães, ao sintetizar o debate norteamericano em torno das ações afirmativas, informa sobre algumas questões centrais em seu interior. A primeira ordem de questões está relacionada com o confronto entre dois valores nucleares daquela sociedade: o igualitarismo e o individualismo. A segunda ordem de questões refere-se às implicações da passagem (ou do deslocamento) de uma tradição jurídica centrada no direito individual para o reconhecimento de direitos coletivos. A terceira ordem de questões, intimamente imbricada com as anteriores, relaciona-se com o questionamento da noção de mérito numa sociedade em que as diferenças naturais foram construídas como desigualdades sociais. E, finalmente, a quarta ordem de questões situa-se na exigência de uma representação diversa na ocupação de posições estratégicas no mercado de trabalho, como forma de diminuir tensões sociais provenientes da sobrerepresentação masculina branca.

Ao identificar duas perspectivas teóricas principais, a axiológica e normativa e a histórica e sociológica, o autor passa a demonstrar a recepção das questões acima descritas em cada uma delas.

De acordo com Guimarães, na perspectiva axiológica e normativa, o argumento central, em torno do qual se debatem três posições, é: "as políticas de ação afirmativa forçaram uma confrontação aguda entre dois valores nucleares da sociedade americana: igualitarismo e individualismo" (Lipset apud Guimarães, 1999, p. I 5). Assim, as políticas de ação afirmativa teriam substituído o igualitarismo, no qual a idéia nuclear é a igualdade de oportunidades para os indivíduos, por uma igualdade de resultados, que transfere a unidade de ação social, econômica e política dos indivíduos para os grupos de pertença identitária (Guimarães, 1999, p. 152).

De acordo com Guimarães, Seymor Martin Lipset conclui que tal tensão só poderá ser desfeita se as políticas de ação afirmativa retomarem "seu objetivo original de garantir tratamento igual para os indivíduos", sugerindo que as novas estratégias, para proporcionar a ascensão social de membros de minorias, "sejam de cunho universalista ou referidas a traços variáveis, tais como pobreza, ao invés de referirem-se a raça, gênero ou etnicidade".

Tudo indica que Lipset retoma o debate proposto por Myrdal na década de 1940, conhecido como o "Dilema americano", substituindo seus termos. Para Myrdal, 
a contradição central situava-se na relação entre o credo universalista, baseado no mérito individual e na igualdade de oportunidades, e as particularidades ou particularismos e hierarquias da vida cotidiana, mormente a segregação e discriminação racial. Para Lipset, em vez de segregação e discriminação raciais aparece agora a pobreza. $\bigcirc$ que em Myrdal era implícito - o direito é a arena dos indivíduos e não dos grupos - em Lipset torna-se explícito. Para Myrdal, o conflito moral ocorria entre as intenções e as ações da maioria branca. Em Lipset o conflito situa-se entre valores individualistas e pertenças grupais. Sua conclusão é que não haveria lugar para direitos de grupos (Lipset apud Guimarães, 1999, p. 152).

Assim, a crítica de Lipset pode ser considerada conservadora, pois atribui aos indivíduos a responsabilidade pela posição social que ocupam, considerando que é indevida qualquer intervenção estável e que não se sustenta diante da tradição liberal americana.

O debate sobre ação afirmativa reflete a evolução do pensamento social que, a partir da década de 60, passou a descobrir e teorizar fenômenos sociais irredutíveis ao indivíduo e a induzir o próprio pensamento liberal e a teoria do direito a buscarem novas formas de compatibilização entre direitos individuais e restrições coletivas à ação individual (Guimarães, I999, p. I 56).

Ora a sobre-representação de pessoas com uma mesma característica "naturalizada", em qualquer distribuição de recursos, deve ser investigada, não porque seja anormal, mas porque "sexo", "cor", "raça”, "etnia" são construções sociais, usadas, precisamente, para monopolizar recursos coletivos. Ações afirmativas são políticas que visam afirmar o direito de acesso a tais recursos a membros de grupos subrepresentados, uma vez que se tenham boas razões e evidências para supor que o acesso seja controlado por mecanismos ilegítimos de discriminação (racial, étnica, sexual). (Guimarães, 1999, p. 158)

A jurisprudência que se forma nos Estados Unidos em torno da legalidade ou não de certas práticas de ação afirmativa busca, justamente, construir pontes entre os direitos coletivos e os direitos individuais. $\bigcirc$ ponto central dessa jurisprudência é a noção de reparação.

A defesa da validade moral das ações afirmativas conduziu a duas outras posições, no interior da perspectiva normativa e axiológica. A posição liberal, enraizada no credo individualista, defende tais ações, baseando-se na idéia de mérito, de igualdade de oportunidades. Uma terceira posição, que abomina tanto a meritocracia quanto o individualismo, defende aquelas ações com base em uma ética política (Guimarães, 1999, p. 163). 
Essa última posição observa que os liberais preferem as políticas universalistas, chamadas color-blind, às politicas particularistas, chamadas race-conscious. Assim, para os defensores do credo individualista é central a idéia de mérito e igualdade de oportunidades. Para os defensores de uma ética política, é fundamental a crítica à meritocracia e ao individualismo.

Um dos principais representantes desta última posição é Duncam Kennedy ( 1995), que chama a posição liberal de "fundamentalismo meritocrático". ○ argumento central da crítica de Kennedy é que, no caso da ação afirmativa, assim como no que se refere ao voto e à liberdade de expressão, o objetivo é político e prévio à realização de ilustração ou à recompensa de "mérito", tal como determinada pelas instituições existentes. $\bigcirc$ valor em causa é a comunidade, e não a capacidade individual.

No fundo o que se quer mostrar é que os valores, em geral, escondem e justificam ações diferentes das que explicitam, ao contrário da crença dos liberais e conservadores de que os valores estruturam e orientam sempre ações específicas.

Assim, o valor supremo a ser perseguido é, portanto, a representação da diversidade cultural e comunitária em todos os âmbitos da vida pública. Aqui fica clara a convicção de que as desigualdades entre os seres humanos é, hoje, produto de subordinação política e cultural. Desse modo, as ações afirmativas poderiam garantir a preservação e o desenvolvimento da diversidade cultural (Guimarães, 1999, p. 163).

De acordo com Guimarães, a perspectiva histórica e sociológica que ganha cada vez mais espaço na literatura enfatiza o modo como políticas de ação afirmativa vieram ou podem vir a se constituir, bem como os impactos que tiveram ou podem vir a ter sobre a estrutura social. Isto é, procura compreender os antecedentes sociais e históricos (sistema de valores, conjunturas políticas, movimentos sociais e ações coletivas) que tornaram ou podem vir a tornar possível a construção de políticas públicas de cunho e de intenção antidiscriminatórios em países plurirraciais ou étnicos de credo democrático. Tais discussões giram ainda em torno dos obstáculos e dos incentivos sociais (o sentido do jogo político e social) para a adoção dessas políticas em situações nacionais concretas.

\section{A DISCUSSÃO BRASILEIRA}

As posições conservadoras de Lipset muito se assemelham às críticas de intelectuais e da imprensa brasileira em relação à ação afirmativa, a meu ver produto da não-atualização dos esquemas interpretativos e conceituais. A distinção é que 
a pobreza, que passou a ser a palavra de ordem da reação conservadora nos EUA, sempre apareceu para os nossos conservadores de forma prioritária na explicação dos problemas sociais. Lá, os negros e as mulheres, aparentemente, estão desafiados a manter as conquistas obtidas com os programas de ação afirmativa, especialmente entre os anos de 1960 e de 1980; aqui, negros e mulheres necessitam lutar para a implementação de políticas públicas e programas que ampliem sua participação em posições estratégicas do mercado de trabalho, em paralelo à crítica feita à sociedade que os inferioriza.

Colocando em outros termos, a questão é saber o quanto custou e custa para os afrodescendentes o juízo de superioridade que opera no Brasil, o qual tem possibilitado a vigência da expressão "juntos mas desiguais" que, ao que tudo indica, temse sobreposto a qualquer conflito moral no interior do grupo dominante branco.

De acordo com Guimarães, a discussão sobre políticas públicas com o fito específico de beneficiar os afro-brasileiros é ainda incipiente no país. Os argumentos contrários vão em três direções:

I. As ações afirmativas significam o reconhecimento de diferenças étnicas e raciais entre os brasileiros, o que contraria o credo nacional de que somos um só povo, uma só raça.

2. Há aqueles que vêem em discriminações positivas um repúdio ao princípio universalista e individualista do mérito que orienta a vida pública brasileira e tem sido a principal arma contra o particularismo.

3. Para outros, simplesmente, não existem possibilidades reais de implementação dessas políticas no Brasil.

Assim, no primeiro caso a negativa de reconhecer a existência formal da discriminação racial, quando ela é denunciada e comprovada, transmuda-se na afirmação de que ela não pode existir porque não somos brancos, porque somos todos mestiços. Esse consenso nacional, todavia, não resiste a um exame mais detalhado. Tudo se passa nessa versão romântica do anti-racismo, como se se quisesse negar uma realidade na qual, no íntimo, acredita-se: declara-se que as raças não existem, mas se usa a classificação de "negros" e "brancos" dos Estados Unidos, como se esta fosse a classificação racial verdadeira, como se os brancos americanos não fossem, eles próprios, também mestiços; como se eles fossem puros, "cem por cento" brancos. Apenas nossos brancos é que seriam mestiços e, por isso, seriam considerados "negros" nos Estados Unidos. 
"Na verdade, é contra essa classificação "odiosa", que nos transformaria, a todos, em negros, que se levanta a nossa indignação, negando as raças e, ao mesmo tempo, a possibilidade de haver discriminação entre nós". Ao se perguntar que "nós" é este?, quem se inclui neste "nós"?, o autor responde: "aparentemente todos os que 'não são ostensivamente de cor'” (Guimarães, 1999, p. 169).

\section{A POLÍTICA EDUCACIONAL E A ESCOLA NA ERA DA AÇÃO AFIRMATIVA}

Existe um certo consenso entre os estudiosos de que as ações afirmativas destinadas a promover a igualdade - o combate à discriminação na área da educação nos EUA é disciplinado no Título VI do Estatuto dos Direitos Civis de 1964 são o resultado da iniciativa de entidades públicas e privadas que buscaram se adequar à política antidiscriminatória patrocinada pelo governo federal.

A materialização dessa adequação ocorreu, e ocorre, por meio de

...programas preferenciais, concebidos e implementados pelas próprias instituições educacionais, ora pela observância estrita das normas proibitivas de discriminação inseridas no Estatuto dos Direitos Civis, ora mediante severa vigilância por parte de órgãos governamentais e entidades de promoção dos direitos de minorias. (Gomes, 200 I, p.94)

Desde o início de sua implantação nos anos 60, logo após a assinatura de um decreto executivo pelo presidente John Kennedy, que determinava a inserção dos negros no sistema educacional de qualidade, somente em 1978 ocorreu a primeira contestação que se tornou pública. $\bigcirc$ caso Regents of the University of California versus Bakke representou um momento fundamental no debate sobre as ações afirmativas na área da educação.

O caso envolvia um programa preferencial de admissão na Faculdade de Medicina da Universidade da Califórnia em Davis. De acordo com esse programa, dezesseis por cento das vagas do curso de Medicina seriam destinadas a estudantes pertencentes a minorias. Num universo de cem vagas, restariam 84 para competição entre outras pessoas não classificadas como minoria. O programa, contudo, tinha uma falha séria em sua concepção, isto era visível ao primeiro contato: para as dezesseis vagas reservadas só podiam concorrer as minorias, mas o inverso não era verdadeiro, ou seja, as minorias também podiam concorrer a uma das 84 vagas restantes!

Por esse e outros motivos, um candidato branco, Alan Bakke, moveu ação contra a Faculdade perante a Justiça Estadual da Califórnia, alegando violação ao seu direito a 
igual proteção da lei ( $14^{a}$ Emenda à Constituição dos EUA), bem como infringência ao Título VI da Lei dos Direitos Civis de 1964. (Gomes, 200 I , p. I 05)

Esse caso colocou em evidência a disputa entre os dois postulados filosóficos das ações afirmativas - a tese da justiça compensatória e a tese da justiça distributiva. Isto é, a disputa entre uma posição que postula que o Estado, para implementar qualquer medida "afirmativa" em prol de minorias, tem que produzir "evidências" da existência da discriminação e apontar as respectivas vítimas; e outra que sustenta que a sub-representação de minorias nas diversas profissões "constitui a prova cabal da discriminação do passado, razão pela qual não haveria a necessidade de que os beneficiários da medida redistributiva proposta sejam as verdadeiras vítimas da discriminação" (Gomes, 200 I, p. I |4).

Para Guimarães, nesse último sentido estaria contida, para além da dimensão redistributiva, a novidade das ações afirmativas como políticas públicas, uma vez que elas podem prevenir que pessoas pertencentes a grupos com grande probabilidade estatística de serem discriminados ou indivíduos de certos grupos de risco tenham seus direitos alienados (Guimarães, 1999, p. 154).

Os comentários de Dworkin sobre o Caso Bakke estendem-se a dois outros desdobramentos fundamentais do debate: o primeiro é a compatibilidade do fator raça com a legislação federal de direitos civis, endossada pelo julgamento da Corte Suprema; o segundo é o entendimento de que a diversidade deve ser compreendida entre os objetivos impostergáveis que toda instituição universitária deve perseguir, enquadrando-se na rubrica da autonomia universitária.

\section{O CASO BRASILEIRO}

que se deve ter em mente é que, sendo as universidades e as faculdades as instituições responsáveis pela formação dos professores que operam nos diferentes graus de ensino em todo o país, o conhecimento de nossa diversidade cultural no plano dos conteúdos ministrados deve acoplar-se à diversidade no plano representacional, isto é, à das pessoas que são formadas nos diferentes cursos. Aqui reside um problema fundamental: se é verdade que o liberalismo recomenda a neutralidade do Estado em alguns domínios, como por exemplo o religioso, o mesmo não ocorre com a educação.

7 Para uma discussão substantiva dos desdobramentos do caso Regents of the University California versus Bakke, consultar, dentre outros, Gomes (200 I , p.93- I30), Menezes (200 I , p.98- I06) e Dworkin (1985, p.293 ss.). 
Assim, a pergunta que deve ser feita é a seguinte: como indivíduos e grupos portadores de identidades raciais e ou étnicas distintas da dominante podem ser representados com eqüidade perante Estados cujas instituições não "reconhecem" as suas identidades particulares, isto é, suas diferenças? (Gomes, 200 I , p.74)

Para Taylor, a identidade do ser humano é parcialmente moldada a partir do reconhecimento, ou da falta deste, ou seja, o modo como ele é representado pelos outros seres humanos pode afetar uma pessoa ou um grupo, de modo a causar sérios danos à medida que aqueles que os cercam tenham uma imagem desprezível ou desdenhosa. Para este autor, a ausência de reconhecimento ou o reconhecimento inadequado pode ser uma das principais fontes de opressão, confinando alguém em um falso, distorcido e reduzido modo de ser (Taylor, 1994, p.26; Silvério, 1999, p.44-55). Essas fontes de opressão ganham visibilidade e efetividade na sociedade em geral e, em especial, no processo educacional em que os conteúdos culturais e os valores sociais são inculcados.

No fundamental, a discussão sobre as relações raciais, no caso brasileiro, inicia-se nas escolas e não no âmbito da política educacional, pela simples (e falsa) negação da existência de racismo, e pode ser considerada um fenômeno muito recente. Ela adquire maior visibilidade a partir das denúncias dos movimentos negros sobre o papel ideológico do mito da democracia racial e, também, de alguns trabalhos realizados a partir da década de 1970, que passaram a demonstrar que as crianças e jovens negros tanto pressionavam mais o mercado de trabalho quanto tinham um menor rendimento escolar e evadiam-se do ensino de primeiro grau em proporção muito maior do que as crianças e jovens brancos (Rosemberg, 1986; Hasenbalg, Silva, 1990).

Quaisquer que sejam as variáveis explicativas do fenômeno da diferença de anos de escolarização entre brancos e negros na atualidade, alguns estudos demonstram que parte do problema está associada ao racismo e à discriminação racial presentes em nossa sociedade em geral e, em especial, na instituição escolar.

Outros estudos demonstram que o racismo e a discriminação racial estão associados à experiência branca. A branquitude (whiteness) "se define como uma consciência silenciada 'quase' incapaz de admitir sua participação provocante em conflitos raciais que resiste, assim, em aceitar e a relacionar-se com a experiência dos que recebem a violação e o preconceito" (Rossato, Gesser, 200 I , p. I I).

Esta consciência silenciada ou experiência branca pode ser definida como "uma forma sócio-histórica de consciência" nascida das relações capitalistas e leis coloniais, hoje compreendida como "relações emergentes entre grupos dominan- 
tes e subordinados". Essa branquitude como geradora de conflitos raciais demarca concepções ideológicas, práticas sociais e formação cultural, identificadas com e para brancos como de ordem "branca" e, por conseqüência, socialmente hegemônica (Rossato, Gesser, 200 I, p. I I).

A experiência branca, ou branquitude, pode então ser observada e compreendida como uma "forma de amnésia social associada a certos modos de subjetividade que, em contextos sociais particulares, são percebidas como normais. De acordo com esse raciocínio, a experiência de outros grupos raciais (negros, pardos em geral, afrodescendentes) é descaracterizada como de seres humanos e, por conseqüência, é percebida como indicadora de desajustes no contexto de humanidade.

O encontro com o "outro" (denominado índio, escravo, preto, negro, nomenclaturas essas estabelecidas para justificar sua desumanidade, invisibilidade e coisificação), não incluído como membro social, permitiu aos colonizadores angloeuropeus perceberem a branquitude como uma representação de identidade e ponto de referência para legitimar a distinção e a superioridade, assegurando assim sua posição de privilégio (Rossato, Gesser, 200 I , p. I3).

No contexto colonial as marcas dessa identidade dominante seriam representadas pela ordem, racionalidade e autocontrole. Os demais grupos raciais seriam vistos como indicadores de caos, irracionalidade, vandalismo e por meio da completa perda da auto-regulação.

Um dos resultados desse contexto histórico foi o movimento de eugenia do final do século XIX (| 880) e início do século XX (1920), que tinha como objetivo manter a raça "pura". Ou seja, pessoas não brancas eram racialmente discriminadas e consideradas inferiores e, conseqüentemente, vítimas de preconceito. $\bigcirc$ termo eugenia, de origem grega, significa "bom de nascimento". A crença estabelecida por meio desse movimento era a de que vários aspectos observados no comportamento humano (moral, social, intelectual) eram considerados hereditários. $\bigcirc$ movimento veiculava também a idéia de que, pela composição hereditária do ser humano, era possível prever sua futura atuação na sociedade. Essa crença, aparentemente, tem mantido um espaço contínuo na consciência popular por mais de um século e afetado gerações.

Da mesma forma que ocorreu em outros países, as premissas do movimento da eugenia trouxeram ao Brasil as explicações para os fenômenos raciais, classificando-os como um exemplo de ineficácia biológica hereditária e fazendo com que, conforme a cor da pele, as pessoas se sentissem (ou se sintam) mais ou menos privilegiadas umas em relação às outras. 
De acordo com a teoria sociocultural da aprendizagem, fatores sociais e culturais exercem um papel crucial no processo de alfabetização de uma criança. Vygotsky ( 1986) explica com sua teoria de desenvolvimento cognitivo que processos psicológicos se relacionam com o ambiente social e cultural. Nessa perspectiva ele enfatiza as conexões entre fatores sociais de natureza cultural e histórica, bem como os de natureza interpessoal. Esse autor salienta que a linguagem não é só instrumento de comunicação, mas também um instrumento que tem dado configuração à evolução cultural dos povos. Dessa forma, as crianças aprendem e internalizam o que se veicula no contexto em que vivem e, no caso específico da discriminação, obviamente elas aprendem e internalizam as representações racistas. Exposta a criança a esta aprendizagem, o racismo internalizado é propagado intra e intergerações. Assim, esse fenômeno não é algo do passado; infelizmente, ele é um dos problemas centrais e perenes em sociedades multirraciais como a brasileira.

Conforme a teoria de Vygotsky ( 1986), esse fenômeno sociocultural vivido na sala de aula propicia a internalização de fatores de aprendizagem discriminatórios que viriam a contribuir e reforçar os esquemas culturais e cognitivos já veiculados no ambiente familiar e comunitário.

O afrontamento de tais barreiras, invisíveis e visíveis, coloca muitas crianças de origem não branca numa posição de resistência. No entanto, outras crianças assumem uma posição chamada, em inglês, racelessness (decomposição racial). Essas crianças abandonam sua tradição cultural ou étnica e se vêem forçadas a usar uma postura e atitude esbranquiçada para serem bem-sucedidas e terem acesso ao grande desejo de "subir na vida" e alcançar assim o objetivo almejado, ou mais próximo do almejado. Esse fenômeno é caracterizado como uma busca de descolonização por meio da imitação do comportamento branco tido como dominante. (Rossato, Gesser, 200।, p.22)

Desenvolvendo essa consciência poderemos encontrar milhões de crianças negras no Brasil e no mundo. Muitas delas sentem-se silenciadas, ou seja, sentem que suas vozes, experiências e histórias não são validadas e ouvidas pela escola.

Assim, em boa medida, o combate à pobreza no Brasil passa necessariamente pela manutenção da criança e do jovem negro na escola. Mas em uma escola de qualidade que consiga transmitir, sem mistificação e de forma mais equânime para todos, a contribuição de cada raça, de cada etnia na formação sociocultural brasileira. A construção de um tal processo escolar depende de uma política educacional que considere, entre outras, duas condições básicas: a inclusão imediata dos 
jovens negros nas universidades por meio de programas de ação afirmativa e a reformulação curricular da formação de professores a partir de parâmetros multiculturais. Dessa forma acredito que o combate ao racismo institucional e às discriminações inscritas em nossas relações sociais terão maior eficácia.

\section{REFERÊNCIAS BIBLIOGRÁFICAS}

ANDREWS, G. Negros e brancos em São Paulo: 1888-1988. São Paulo: Edusp, 1998.

AVRITZER, L.; DOMINGUES, J. M. (org.). Teoria social e modernidade no Brasil. Belo Horizonte, 2000.

BARROS, R. P.; MENDONÇA, R. S. Diferenças entre discriminação racial e por gênero e o desenho de políticas antidiscriminatórias. Estudos Feministas, n. I , p. I 83-193, 1996.

BENTO, M. A. S. Racismo no trabalho: o movimento sindical e o Estado. In: GUIMARÃES, A. S. A. Tirando as máscaras: ensaios sobre racismo no Brasil. São Paulo: Paz e Terra; SEF, 2000, p. 17-30.

CARMICHEL, S; HAMILTON, C.V. Black power the politics of liberation. London: Jonathan Cape, 1968.

CARNEIRO, S. Estratégias legais para promover a justiça social. In: GUIMARÃES, A. S. A. Tirando as máscaras: ensaios sobre racismo no Brasil. São Paulo: Paz e Terra; SEF, 2000, p.3। I-323.

COMPARATO, F. O Princípio da igualdade e a escola. Cadernos de Pesquisa, n. I 04, p.47-57, jul. 1998.

COSTA, E. V. The Brazilian empire: myths and history. Chicago: University of Chicago Press, 1985.

CRENSHAW, K. W. Color-blind dreams and racial nightmares: reconfiguring racism in the post-civil rights era. In: MORRISON, T.; LACOUR, C. B. (orgs.). Birth of a Nation'hood. New York: Pantheon, 1997, p.99.

DAMATTA, R. Notas sobre o racismo à brasileira. In: SOUZA, J. (org.). Multiculturalismo e racismo: o papel da ação afirmativa nos Estados democráticos contemporâneos. Brasilia: Ministério da Justiça, 1996, p.69-74.

DWORKIN, R. Freedom's law: the moral reading of the american constitution. Cambridge: Harvard University Press, 1996.

As Matter of principle. Cambridge: Harvard University Press, 1985.

Taking rights seriously. Cambridge: Harvard University Press, 1978. 
FRY, P. O Que a Cinderela negra tem a dizer sobre a "política racial" no Brasil. Revista USP, n. 28, 1995/1996 (Dossiê povo negro - 300 anos).

GILLIAM, A. Globalização, identidade e os ataques à igualdade nos Estados Unidos: esboço de uma perspectiva para o Brasil. In: CAPINHA, G.; FELDMAN-BIANCO, B. (orgs.). Identidades: estudos de cultura e poder. São Paulo: Hucitec, 2000, p.73- 105.

GILROY, P. There ain't no black in the union jack. Londres: Hutchinson, 1987.

GIROUX, H. Por uma pedagogia e política da branquidade. Cadernos de Pesquisa, n. I07, p.97-|32, jul. 1999.

GOMES, J. Ação afirmativa e princípio constitucional da igualdade: o direito como instrumento de transformação social; a experiência dos EUA. Rio de Janeiro; São Paulo: Renovar, 2001.

GUIMARÃES, A . S. A Desigualdade que anula a desigualdade: notas sobre a ação afirmativa no Brasil. In: SOUZA, J. (org.). Multiculturalismo e racismo: o papel da ação afirmativa nos Estados democráticos contemporâneos. Brasília: Ministério da Justiça, 1996, p.233-242.

Racismo e anti-racismo no Brasil. São Paulo: Editora 34, 1999.

GUSMÃO, N. M. M. de. Linguagem, cultura e alteridade: imagens do outro. Cadernos de Pesquisa, n. 107, p.41-78, jul. 1999.

HALL, S. Gramsci's relevance for the study of race and ethnicity. Journal of Communication Inquiry, v. 10, n. 2, p.5-27, summer 1986.

Race, articulation and societies structured in dominance. In: Sociological theories: race and colonialism. Paris: Unesco, p.323-363, 1980.

Race, culture and communications: looking backward and forward at cultural studies. Rethinking Marxism, v. 5, n. I, p. 10 - 18, spring 1992.

HANCHARD, M. Americano, brasileiros e a cor da especificidade humana: uma resposta a Peter Fry. Revista USP, n. 3 I, p. 164- 175, 1996.

Orfeu e o poder: o movimento negro no Rio de Janeiro e São Paulo ( $1945-$ 1988). Rio de Janeiro: Ed. Uerj, 2001.

HASENBALG, C.; SILVA, N. Raça e oportunidades educacionais no Brasil. Estudos AfroAsiáticos. Rio de Janeiro, n. 18, p.73-91, maio 1990.

Relações raciais no Brasil. Rio de Janeiro: Rio Fundo, 1992.

HENRIQUES, R. Desigualdade racial no Brasil: evolução das condições de vida na década de 90. Rio de Janeiro: IPEA, 200 I. [Texto para discussão n. 807]

HERING, R. Addressing race inequalities in Brazil. some lessons from the United States. Washington, DC: Latin American Program; Woodrow Wilson International Center for Scholars, 1998. [Working Paper Series; n. 237] 
. A Agenda anti-racista das ONGs brasileiras nos anos 90. In: GUIMARÃES, A. S. A. Tirando as máscaras. ensaios sobre racismo no Brasil. São Paulo: Paz e Terra; SEF, 2000. HOFBAUER, A. Uma história de branqueamento ou o negro em questão. Tese [Dout.] USP/ FFLCH - Departamento de Antropologia, São Paulo, 1999.

JONES, J. The Rise and fall of affirmative action. In: HILL, H.; JONES, J. (eds.). Race in America: the struggle for equality. Madison: Univesity of Wisconsin Press, 1993.

KENNEDY, D. A Cultural pluralist case for affirmative action in legal academia. In: CRENSHAW, K. et al. Critical race theory. New York: The New Press, 1995, p. 162.

KREUTZ, L. Identidade étnica e processo escolar. Cadernos de Pesquisa. n. I07, p.79-96, jul., 1999.

LIMA, D. O Enfrentamento do racismo em um projeto democrático: a possibilidade jurídica. In: SOUZA J. (org.). Multiculturalismo e racismo: o papel da ação afirmativa nos Estados democráticos contemporâneos. Brasília: Ministério da Justiça, 1996, p. 1 89-208.

MCLAREN, P. Whiteness is... the struggle for postcolonial hy bridity. In: KINCHELOE, J. et al. Deploying whiteness in America. Nova York: St. Martin's Griffin, 1998.

MENEZES, P. A Ação afirmativa (affirmative action) no direito norte-americano. São Paulo: Editora dos Tribunais, 2001 .

MILES, R. Racism. New York: Routledge, 1989. [Key ideas series]

. Racism and migrant labour. a critical text. London: Routledge \& Kegan Paul, 1982.

OMI, M.; WINANT, H. Racial formation in the United States. from the 1960 to the 1980s. New York: Routledge, 1994.

OUTHWAITE, W.; BOTTOMORE, T. (eds.). Dicionário do pensamento social do século XX. Rio de Janeiro: Zahar, 1996.

REIS, F. Mito e valor da democracia. In: SOUZA, J. (org.). Multiculturalismo e racismo: o papel da ação afirmativa nos Estados democráticos contemporâneos. Brasília: Ministério da Justiça, 1996, p.221-232.

ROSEMBERG, F. et. al. Diagnóstico sobre a situação educacional de negros (pretos e pardos) no Estado de São Paulo. 2 v. São Paulo: Fundação Carlos Chagas, 1986.

Relações raciais e rendimento escolar. Cadernos de Pesquisa, n. 63, p. 19-23, nov. 1987.

ROSSATO, C.; GESSER, V. A Experiência de branquitude diante dos conflitos raciais: estudos de realidades brasileiras e estadunidenses. In: CAVALLEIRO, E. (org.). Racismo e anti-racismo na educação: repensando nossa escola. São Paulo: Selo Negro, 200 I , p. I I-36. 
SANSONE, L. Racismo sem etnicidade: políticas públicas e discriminação racial em perspectiva comparada. DADOS - Revista de Ciências Sociais, v. 4I , n. 4, p.75I-783, 1998.

SILVA, J. Política de ação afirmativa para a população negra: educação, trabalho e participação no poder. FLACSO, 1999.[Working Paper]

SILVA Jr., H. Do racismo legal ao princípio da ação afirmativa: a lei como obstáculo e como instrumento dos direitos e interesses do povo negro. In: GUIMARÃES, A. S. A. Tirando as máscaras: ensaios sobre racismo no Brasil. São Paulo: Paz e Terra/SEF, 2000, p.359-387.

SILVÉRIO, V. O Multiculturalismo e o reconhecimento: mito e metáfora. Revista USP, n. 42, p.44-55, jun. ago. 1999.

Raça, racismo na virada do milênio: os novos contornos da racialização.

Campinas, 1999a. Tese [Dout.] Unicamp, IFCH - Departamento de Sociologia.

SOUZA, J. (org.). Multiculturalismo e racismo: o papel da ação afirmativa nos Estados democráticos contemporâneos. Brasília: Ministério da Justiça, p.23-35, 1996.

TAYLOR, C. The Politics of recognition. In: GUTMAN, A. et. al. (org.). Examinig the politics of recognition. New Jersey: Princeton University Press, 1994. p.23-46.

TELLES, E. Início no Brasil e fim nos EUA? Estudos Feministas, n. I, p. 194-201 , 1996.

TELLES, V. da S.; PAOLI, M. Direitos sociais. conflitos e negociações no Brasil contemporâneo. São Paulo: USP/FFLCH, 1996. [Working Paper]

VYGOTSKY, L. Thought and language. Cambridge: MIT Press, 1986.

WILLIAMS, J. Redifining institucional racism. Ethnic and racial studies, v. 8, n. 3, p.323 - 328, 1985.

WINANT, H. Racial condition: politics, theory, comparisons. Minneapolis; London: University of Minnesota Press, 1996.

Recebido em: julho 2002

Aprovado para publicação em: agosto 2002 